\title{
SEXUAL AND GENITAL PROGNOSIS IN ADULT PARAPLEGICS
}

\author{
By Dr. PIERA ANDres \\ Hôpital Poincaré, Garches, Paris, France ${ }^{1}$
}

\section{Abstract}

This is a summary of a paper of which there was no time for it to be properly translated before its presentation, and concerns the Ioo last patients who came to our consultation.

IN general, erections are more frequent than ejaculations, but the study of the results do not take any value only considering the spinal cord lesion.

In complete spastic lesions the reflex erections are the rule, and are evoked by the least stimulus. Ejaculations are more rare, approximately in one-third of the cases. Coitus is possible under difficulties due to the motor handicap, but if these difficulties can be solved, erection will occur. Twenty cases with complete spastic paraplegia have been particularly studied with regard to the possibilities of ejaculation, if necessary with prostigmine test.

Results of Prostigmine Tests. There were five successes with rather good sperm in complete spastic lesions, the spasticity being below Tio. Seven trials with seven successes with average sperm were made. Nine trials have been made with nine failures. If the spasticity is above Tro, that is, if the upper limit of the reflexogenic zone is above TIo, ejaculation is possible. In complete flaccid lesions, four attempts have been made with four failures. The results obtained are valuable according to the neurological level.

The value of the obtained ejaculation is, as a rule, average or mediocre, as far as the number of sperms and their motility are concerned. If the level of spasticity remains below TII, there is no ejaculation in spite of the prostigmine test. One has to remember that the centres of the erection and ejaculation are situated below Tio and, therefore, these negative results are not surprising.

In the complete, flaccid lesion the prognosis is very bad; there is no possibility of erection or ejaculation except in the very exceptional cases. Four cases have received the prostigmine test and in one case it was performed three times at monthly intervals without obtaining erection or ejaculation. One exception of this was a subject with an incomplete lesion from $\mathrm{L}_{\mathrm{I}}$ to $\mathrm{S}_{4}$ and complete only below $\mathrm{S}_{4}$. In this case erections and ejaculations were of good quality as the lesion was below the spinal sexual centres, his sperms were normal and a child was conceived. But, this exception confirms the rule. As far as the incomplete spastic lesions are concerned, the erections which are more reflex than psychogenic are very often accompanied by ejaculations, if necessary evoked by a prostigmine test. In the incomplete spastic lesions the sperms are generally of good quality and, moreover, better if the lesion is distantly situated. The prognosis is also better in incomplete flaccid lesions and ejaculation is often possible; if necessary elicited by a prostigmine test. A paraplegic of the level LI has been able since his accident to sire two children by normal coitus.

1 Translated by Dr. Dolfus. 